\title{
Refuge availability increases kelp consumption by purple sea urchins exposed to predation risk cue
}

\author{
Lindsay A. Green* \\ Marine Science Center, Northeastern University, 430 Nahant Road, Nahant, Massachusetts 01908, USA \\ Present address: Department of Biological Science, University of New Hampshire, 46 College Road, Durham, \\ New Hampshire 03824, USA
}

\begin{abstract}
Predator-prey interactions in kelp forests have been a topic of research for many decades. Prey anti-predator behaviors (e.g. reducing foraging) are an important component of predator-prey interactions and can cause impacts on primary producers (trait-mediated indirect interactions, TMIIs). In kelp forests, the interactions between spiny lobsters and their sea urchin prey can have significant impacts on kelp biomass. In a laboratory mesocosm experiment, I found that both spiny lobster Panulirus interruptus waterborne risk cue and urchin refuge availability significantly affected kelp Macrocystis pyrifera consumption by urchins Strongylocentrotus purpuratus. However, the effect of predator risk cue on kelp consumption was magnified in the absence of an urchin refuge. This study provides further evidence that TMIIs are important in lobster-urchin interactions, and suggests that refuge availability, by influencing foraging behavior, may also shape the important role of urchins in kelp forests.
\end{abstract}

KEY WORDS: Trait-mediated indirect interactions $\cdot$ Refuge $\cdot$ Kelp forest $\cdot$ Strongylocentrotus purpuratus $\cdot$ Panulirus interruptus $\cdot$ Macrocystis pyrifera

\section{INTRODUCTION}

Recently, many studies (Trussell et al. 2002, 2006, Matassa 2010) have examined how changes in prey traits (e.g. behavior, development, and growth) in response to chemical cues released from predators can drive trophic cascades through trait-mediated interactions (TMIs). In the presence of predator risk cue, consumers must carefully assess the trade-off between activity and potential mortality (Werner \& Anholt 1993). Reductions in activity such as foraging can reduce impacts on primary producers (traitmediated indirect interactions, TMIIs) and the risk of predation (Lima \& Dill 1990). Retreat to protective refuge can also decrease predation risk (Trussell et al. 2006).
Kelp forests are shallow coastal communities in cold-water regions (Tegner \& Dayton 2000, Steneck et al. 2002). Kelp genera vary regionally, and the giant forest-forming kelp Macrocystis is dominant along the coasts of northwest and South America. The biological structure of kelp provides a habitat for a remarkable diversity of species (Graham et al. 2007), many of which are important to fisheries (Tegner \& Dayton 2000). Sea urchins are key herbivores in kelp forests and are the most common and important cause of kelp deforestation at mid-latitudes (Steneck et al. 2002).

Spiny lobsters are an important predator controlling the abundance of sea urchins in rocky habitats in Southern California (Winget 1968), and many studies have noted the important role of predation in urchin- 
kelp interactions (e.g. Freeman 2006). Lafferty (2004) reported that overfishing of spiny lobsters led to an explosion in urchin populations and subsequent losses of kelp biomass. The behavioral response of urchins to risk cue has also been documented (Scheibling \& Hamm 1991, Hagen et al. 2002, McKay \& Heck 2008), most recently by Matassa (2010), who reported that urchins reduced their foraging on kelp by $44 \%$ in response to lobster risk cue. Previous studies have also noted the importance of topographic complexity (Grabowski 2004) and refuge availability (Hagen \& Mann 1994, Trussell et al. 2006) on trophic interactions.

Here, I examine how refuge availability affects sea urchin grazing on kelp in the presence of waterborne spiny lobster predation risk cue (i.e. TMIIs) in the tritrophic kelp forest food chain consisting of Panulirus interruptus, Strongylocentrotus purpuratus, and Macrocystis pyrifera. This study tests the hypothesis that urchins with refuges will consume more than urchins without refuges in the presence of spiny lobster risk cue.

\section{MATERIALS AND METHODS}

In the spring of 2009, I conducted an $11 \mathrm{~d}$ experiment to determine the grazing response of purple sea urchins Strongylocentrotus purpuratus to the waterborne predation risk cue of the spiny lobster Panulirus interruptus when given access to refuges at the Wrigley Marine Science Center (WMSC) on Santa Catalina Island, California, USA. Previous studies conducted for $7 \mathrm{~d}$ failed to elucidate responses from urchins (Matassa 2010), so a longer duration was chosen. Initially, a preliminary grazing study was conducted to determine a suitable artificial refuge. Structures tested include teepee, shelf, and hollow tube-shaped refuges (to mimic the shapes of habitats that urchins were observed inside of during field surveys), and kelp consumption was highest in urchins given a teepee-shaped refuge (data not shown).

Sixteen tanks $(60 \times 90 \times 30 \mathrm{~cm}$, width $\times$ length $\times$ height) with independent drains and flow-through seawater $\left(16\right.$ to $\left.18^{\circ} \mathrm{C}\right)$ were divided into 5 sections: 1 central lobster section $(60 \times 30 \times 30 \mathrm{~cm})$ and 4 adjacent sections $\left(30 \mathrm{~cm}^{3}\right)$ to house individual urchins, using acrylic egg crate with $1 \mathrm{~cm}$ mesh size. To minimize urchin interactions, 2 of the 4 corner sections remained empty in each tank. Eight of the tanks contained lobsters and 8 remained lobster-free controls. Teepee-shaped urchin refuges made from two $12 \times$ $8 \mathrm{~cm}$ pieces of white Plexiglas were used to mimic natural refuges and secured to the side of the tank. Water flow was tested using dye to ensure that waterborne predation risk cue would be dispersed equally. In each tank, one corner section on each side received an urchin, and a refuge was randomly assigned to a single urchin per tank. Thus, I had 4 urchin treatment groups (lobster, no refuge; lobster, refuge; no lobster, no refuge; no lobster, refuge) with 8 urchins in each for a total of 32 purple sea urchins.

Eight similarly sized California spiny lobsters were randomly selected from a group trapped within $1 \mathrm{~km}$ of WMSC (carapace length: $7.1 \pm 0.6 \mathrm{~cm}$, mean $\pm \mathrm{SD}$ ). Lobsters bearing eggs were excluded from the experiment, and 8 of the 16 tanks were randomly assigned a lobster. The lobsters were allowed to acclimate in the experimental tanks for at least $24 \mathrm{~h}$. Lobsters were fed $7.5 \pm 0.5 \mathrm{~g}$ of mackerel starting on the day of the experiment and every other day thereafter. Mackerel not consumed within $24 \mathrm{~h}$ was removed. In a preliminary study testing the effects of lobster risk cue on urchin grazing, mackerel was also placed in the lobster-free control tanks and any confounding effects of mackerel were ruled out (data not shown). Purple sea urchins were collected from rocky areas $(<5 \mathrm{~m})$ with low to medium algal growth within $1 \mathrm{~km}$ of WMSC. Urchins with a minimum test diameter of $37 \mathrm{~mm}$ were used in the study. All animals (urchins and lobsters) were maintained and fed in large aquarium tanks and starved for $8 \mathrm{~d}$ prior to the experiment to ensure that all animals started the experiment with the same food history.

Pieces of giant forest-forming kelp were collected from floating drift patches within $1 \mathrm{~km}$ of WMSC and cut into $10 \times 5 \mathrm{~cm}$ rectangular pieces. Care was taken to choose sections of kelp free of fouling organisms and wear. Kelp sections were pre-cut and allowed to heal for $24 \mathrm{~h}$. Five randomly selected kelp pieces were blotted dry, weighed together using a digital scale $( \pm 0.001 \mathrm{~g})$, and placed in each urchin section. Over the $11 \mathrm{~d}$ experiment, the kelp was replaced twice, on Days 4 and 7 , in order to keep the kelp fresh, and wet weights were taken at the time of replacement. Drift kelp was collected and cut $24 \mathrm{~h}$ prior to placement in the tanks each time. Five randomly selected kelp pieces were also placed in the central section in lobster-free control tanks $(\mathrm{n}=8)$ to account for natural weight loss. Kelp consumption was calculated by subtracting the final kelp wet weight from the initial kelp wet weight and summing the kelp consumed over the duration of the experiment. Urchins were observed grazing on kelp in the open and carrying kelp into refuges, although urchins in the 
presence of a lobster were observed more frequently in refuges with kelp.

Total kelp consumption was analyzed using a splitplot design ANOVA (Gotelli \& Ellison 2004) with lobster risk cue and refuge as fixed effects. The data set was analyzed for outliers using the Dixon test (Sokal \& Rohlf 1981). One urchin was determined to be an outlier within its treatment group (no lobster, no refuge) based on negligible kelp consumption (2.1 times below the standard deviation), and coupled with biological observations (i.e. no movement), this urchin was excluded from the analysis. All assumptions were met and analyses were conducted using the JMP statistical package (version 9.0).

\section{RESULTS}

A 2-way ANOVA revealed a significant effect of lobster risk cue $\left(F_{1,13}=13.34, \mathrm{p}=0.0025\right)$ and refuge $\left(F_{1,13}=6.9, \mathrm{p}=0.0209\right)$ on kelp consumption by urchins. The interaction between lobster risk cue and refuge was statistically significant $\left(F_{1,13}=5.4, \mathrm{p}=\right.$ 0.0370 ); therefore, the effects were not independent. The average difference in kelp consumption by urchins between the control (no lobster) and lobster risk cue treatment with a refuge was $3.47 \mathrm{~g}$, while without a refuge the difference was $6.75 \mathrm{~g}$ (Fig. 1). A post hoc Tukey HSD test revealed that urchins exposed to waterborne lobster risk cue with no refuge consumed significantly less kelp than all other treatments, eating $44 \%$ of what urchins exposed to

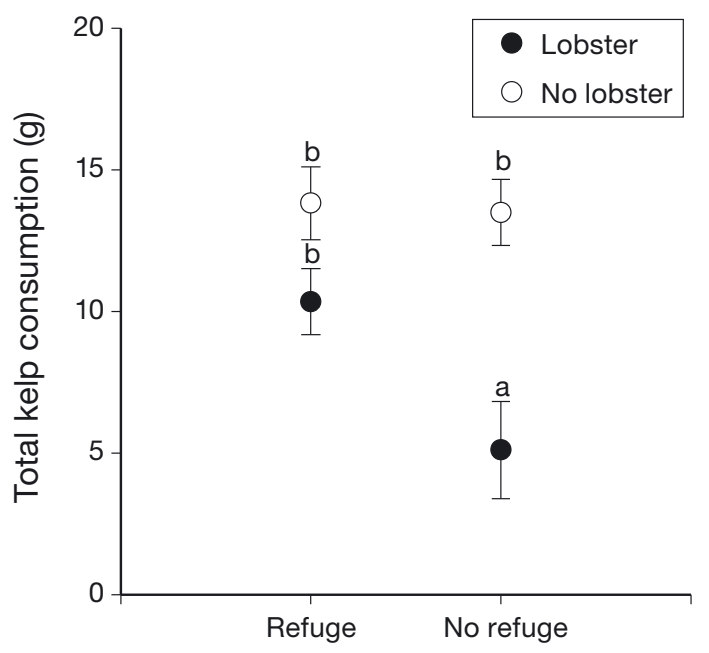

Fig. 1. Macrocystis pyrifera, Strongylocentrotus purpuratus, and Panulirus interruptus. Total adjusted kelp consumption (mean \pm SE) by purple urchins with and without refuges, in the presence or absence of lobsters. Data points with different letters are significantly different cue with a refuge ate, $34 \%$ of what urchins in the absence of cue and a refuge ate, and $32 \%$ of what urchins in the absence of cue with a refuge ate.

\section{DISCUSSION}

Results from this experiment suggest that while waterborne predator risk cue and refuge availability both influence the strength of urchin-kelp interactions by affecting urchin grazing behavior, their effects are dependent on one another. This relationship was demonstrated clearly by the larger effect of lobster risk cue in the absence of a refuge (Fig. 1). This suggests that urchins given access to refuges will continue foraging, whether in the presence or absence of a predator, suggesting that refuge availability may mitigate the impact of waterborne predator risk cue in the natural environment. Trussell et al. (2006) reported similar results, showing that snails responded less to crab risk cue if they resided in a refuge.

Many studies have reported the impact of waterborne predator risk cue in kelp forests. Matassa (2010) reported decreased foraging of purple sea urchins on kelp in the presence of risk cue from spiny lobsters regardless of lobster diet. Studies have also suggested that refuge availability and complexity can alter TMIIs (Hagen \& Mann 1994, Grabowski 2004, Trussell et al. 2006). My results are consistent with Matassa (2010) and Trussell et al. (2006), but additionally provide evidence that refuge availability is important in lobster-urchin interactions. However, as with all laboratory investigations, the present study is limited. In order to determine whether these patterns occur in nature, future studies with field manipulations must be conducted. Another potential limitation is the confounding effects of urchin and urchin grazing cues on herbivory, since 2 urchins were in each tank. Matassa (2010) found no difference in urchin grazing in the presence or absence of cues from damaged conspecifics. Therefore, the effect of urchin and urchin grazing cues on herbivory in my experiment were most likely minimal.

The giant forest-forming kelp Macrocystis pyrifera is a foundation species, creating a habitat that harbors tens to hundreds of species, most of which feed either on Macrocystis-derived carbon or within a subweb founded on Macrocystis-based herbivores (Graham et al. 2007). Spiny lobsters are one of 4 predators in California (along with sea otters, sunflower stars, and California sheephead wrasse) that can consume adult sea urchins. Therefore, TMIIs 
may allow a smaller lobster population to control urchin grazing of kelp forests, since TMIIs can affect many individuals at once (Graham et al. 2007). Without predation of urchins, overgrazing can occur and lead to transitions from kelp forests to urchin barrens, resulting in the loss of species that depend on kelp (Graham et al. 2007).

These findings support growing evidence that TMIIs are an important aspect of kelp forests and that refuge availability is an important factor influencing trade-off decisions. Refuge availability was shown to alter the strength of TMIIs in this tri-trophic food chain. On a broader scale, the current findings suggest that predator risk cue and refuge availability are important in lobster-urchin interactions and may impact the role of urchins in kelp forests. Future studies involving this tri-trophic food chain and others should investigate the effects of refuge availability and TMIIs in field manipulations.

Acknowledgements. Special thanks go to S. Genovese for advising on this project. Thanks also to G. C. Trussell and C. M. Matassa. Thanks to L. Czarnecki, K. Spafford, and WMSC for providing materials and space for the project. This manuscript was greatly improved by the comments of 4 anonymous reviewers. This research partially fulfilled the requirements for the Professional Science Masters (PSM) in Marine Biology degree at Northeastern University and was funded by the Three Seas Program. This is Contribution No. 284 of the Marine Science Center and Contribution No. 11 of the PSM in Marine Biology at Northeastern University.

\section{LITERATURE CITED}

Freeman A (2006) Size-dependent trait-mediated indirect interactions among sea urchin herbivores. Behav Ecol 17: 182-187

Gotelli NJ, Ellison AM (2004) A primer of ecological statistics. Sinauer Associates, Sunderland, MA

Grabowski JH (2004) Habitat complexity disrupts predatorprey interactions but not the trophic cascade on oyster reefs. Ecology 85:995-1004

Editorial responsibility: Christine Paetzold, Oldendorf/Luhe, Germany
Graham MH, Vasquez JA, Buschmann AH (2007) Global ecology of the giant kelp Macrocystis: from ecotypes to ecosystems. Oceanogr Mar Biol Annu Rev 45:39-88

> Hagen N, Mann KH (1994) Experimental analysis of factors influencing the aggregating behaviour of the green sea urchin Strongylocentrotus droebachiensis (Müller). J Exp Mar Biol Ecol 176:107-126

> Hagen N, Anderson A, Stabell O (2002) Alarm responses of the green sea urchin, Strongylocentrotus droebachiensis, induced by chemically labeled durophagous predators and simulated acts of predation. Mar Biol 140:365-374

> Lafferty KD (2004) Fishing for lobsters indirectly increases epidemics in sea urchins. Ecol Appl 14:1566-1573

> Lima SL, Dill LM (1990) Behavioural decisions made under the risk of predation: a review and prospectus. Can J Zool 68:619-640

> Matassa CM (2010) Purple sea urchins Strongylocentrotus purpuratus reduce grazing rates in response to risk cues from the spiny lobster Panulirus interruptus. Mar Ecol Prog Ser 400:283-288

McKay KC, Heck KL (2008) Presence of the Jonah crab Cancer borealis significantly reduces kelp consumption by the green sea urchin Strongylocentrotus droebachiensis. Mar Ecol Prog Ser 356:295-298

> Scheibling RE, Hamm J (1991) Interactions between sea urchins (Strongylocentrotus droebachiensis) and their predators in field and laboratory experiments. Mar Biol 110:105-116

Sokal RR, Rohlf FJ (1981) Biometry, 2nd edn. WH Freeman, San Francisco, CA

> Steneck RS, Graham MH, Bourque BJ, Corbett D, Erlandson JM, Estes JA, Tegner MI (2002) Kelp forest ecosystems: biodiversity, stability, resilience and future. Environ Conserv 29:436-459

> Tegner MJ, Dayton PK (2000) Ecosystem effects of fishing in kelp forest communities. ICES J Mar Sci 57:579-589

> Trussell GC, Ewanchuk PJ, Bertness MD (2002) Field evidence of trait-mediated indirect interactions in a rocky intertidal food web. Ecol Lett 5:241-245

> Trussell GC, Ewanchuk PJ, Matassa CM (2006) Habitat effects on the relative importance of trait- and densitymediated indirect interactions. Ecol Lett 9:1245-1252

> Werner EE, Anholt BR (1993) Ecological consequences of the trade-off between growth and mortality rates mediated by foraging activity. Am Nat 142:242-272

Winget RR (1968) Trophic relationships and metabolic energy budget of the California spiny lobster, Panulirus interruptus (Randall). MS thesis, San Diego State University, CA

Submitted: May 2, 2012; Accepted: August 6, 2012

Proofs received from author(s): October 17, 2012 